\title{
openheart Atrial fibrillation in patients with an atrial septal defect in a single centre cohort during a long clinical follow-up: its association with closure and outcome of therapy
}

Reinder Evertz (D) , ${ }^{1}$ Manon Reinders, ${ }^{1}$ Charlotte Houck, ${ }^{2}$ Tim ten Cate, ${ }^{1}$ Anthonie L. Duijnhouwer (D) , ${ }^{1}$ Rypko Beukema, ${ }^{1}$ Sjoerd Westra, ${ }^{1}$ Kevin Vernooy (1) , ${ }^{3}$ Natasja M S de Groot ${ }^{2}$

\begin{abstract}
- Additional material is published online only. To view please visit the journal online (http://dx.doi.org/10.1136/ openhrt-2020-001298).
\end{abstract}

To cite: Evertz R, Reinders M, Houck C, et al. Atrial fibrillation in patients with an atrial septal defect in a single centre cohort during a long clinical follow-up: its association with closure and outcome of therapy. Open Heart 2020;7:e001298. doi:10.1136/ openhrt-2020-001298

$\mathrm{RE}$ and MR contributed equally.

Received 27 March 2020 Revised 29 May 2020 Accepted 27 June 2020

\section{Check for updates}

C) Author(s) (or their employer(s)) 2020. Re-use permitted under CC BY-NC. No commercial re-use. See rights and permissions. Published by BMJ.

${ }^{1}$ Cardiology, Radboud University Medical Centre, Nijmegen, The Netherlands

${ }^{2}$ Cardiology, Erasmus MC Rotterdam, Zuid-Holland, The Netherlands

${ }^{3}$ Cardiology, Maastricht University Medical Centre, Maastricht, The Netherlands

Correspondence to Dr Reinder Evertz; reinder. evertz@radboudumc.nl

\section{ABSTRACT}

Objective Currently, consensus is lacking on the relation between closure of atrial septal defect (ASD) and the incidence of atrial fibrillation (AF), which is a known complication in ASD patients. More importantly, studies reporting on the treatment applied for AF in ASD patients are scarce. The aims of this study were (1) to assess the incidence of AF in ASD patients, (2) to study the relation between closure and AF and (3) to evaluate applied treatment strategies.

Methods A single-centre retrospective study in 173 patients with an ASD was performed. We analysed the incidence of $A F$, the relation of AF with closure, method of closure and the treatment success of therapies applied. Results Almost $20 \%$ of patients with an ASD developed AF, with a mean age of $59( \pm 14)$ years at first presentation of AF during a median clinical follow-up of 43 (29-59) years. Older age $(0 R 1.072 ; p<0.001)$ and a dilated left atrium (OR $3.727 ; p=0.009$ ) were independently associated with new-onset AF. Closure itself was not independently associated with AF. First applied treatment strategy was rhythm control in $77 \%$. Of the 18 patients treated with antiarrhythmic drugs $50 \%$ had at least 1 recurrence of $\mathrm{AF}$.

Conclusion No clear relation between closure of the ASD and AF could be assessed. This is the first study describing applied therapy for AF in ASD patients of which medical rhythm control was the most applied strategy with a disappointing efficacy.

\section{OBJECTIVE}

Atrial septal defect (ASD) is one of the most common congenital heart diseases (CHD). ASDs have a reported birth prevalence of 1-2 per 1000 live births. ${ }^{1-3}$ As these patients age, atrial tachyarrhythmia, mainly atrial fibrillation (AF), is the most common complications. ${ }^{4-6}$ New-onset AF appears at a younger age in patients with an ASD compared with the general population. ${ }^{48}$ Most patients present

\section{Key questions}

What is already known about this subject?

- Atrial fibrillation (AF) is a well-known complication of an atrial septal defect (ASD), but the relation with closure and the technique of closure as well as the optimal treatment strategy is less clear.

What does this study add?

- With this study, we wanted to answer the question whether the risk of developing AF is related to closure of the ASD, type of closure (whether surgical or percutaneous) or to the presence of an ASD itself and to establish the preferred treatment strategy in clinical practice and its results on AF recurrence.

How might this impact on clinical practice?

- The latter may give insights in the treatment options in this specific patient group, providing evidence for the need of optimising therapy targeting AF in ASD patients.

the first symptoms at adult age. Closure of the defect seems to improve survival, even in adults, but the effect of closure on the incidence of AF is debatable ${ }^{67}$ Previous studies have examined the impact of ASD closure on development of AF. Scarring after surgical closure was hypothesised as a possible cause of AF. However, no difference was seen in the incidence of $\mathrm{AF}$ in surgical compared with percutaneous closure, not supporting this hypothesis of scar related $\mathrm{AF}^{9-11}$ Closure of the ASD was also suggested to be an effective treatment for $\mathrm{AF}$ or even prevent $\mathrm{AF}$ in patients with an ASD. Nevertheless, patients with a history of atrial tachyarrhythmias before closure are more likely to have atrial tachyarrhythmias recurrence after closure. $^{4812}$ More recent studies evaluating the long-term incidence of $\mathrm{AF}$ in relation to 
closure show no significant advantages of closure. ${ }^{1011}$ Thus, it remains uncertain whether ASD closure sufficiently decreases the risk of development of AF in this specific patient group. Moreover, specific treatment strategies, other than closing the defect itself, in ASD patients are scarce and so more data on the applied therapy for AF in patients with an ASD and its results is needed.

The aims of this study were (1) to assess the incidence of AF in ASD patients, (2) to study the relation between closure and AF and (3) to evaluate the applied treatment strategies including rhythm and rate control. Overall, this study will help to clarify the need for close follow-up of ASD patients and justify the need for evidence regarding the best treatment and timing of treatment for AF in ASD patients.

\section{METHODS}

Clinical data were obtained through medical record analysis and were stored anonymised in a separate database. No personal data were stored. Data of patients, who objected to the use of their records, were excluded. In accordance with the General Data Protection Regulation of the European Union informed consent was not required. There is no patient or public involvement in the design or execution of this study.

\section{Study population}

A total of 298 patients were extracted from the outpatient clinic follow-up database, containing patients with CHD, using the "echocardiographic code list" and selecting all patients coded as ASD. Patients with other CHD, diagnosis of AF before the age of 18 years and patients with limited medical records were excluded.

Clinical characteristics were collected from the medical records. We defined end of the follow-up as the last available ECG or death. Medical records were reviewed until December 2016.

\section{Clinical outcomes}

Outcomes included the incidence of AF in ASD patients, the relation between closure of the ASD and development of $\mathrm{AF}$ and the evaluation of therapy outcome of the different treatment strategies applied. AF was defined according to current guidelines as an irregular rhythm combined with a clear beat-to-beat variation in the morphology of atrial waves with a duration of more than 30s. ${ }^{13}$ We defined new-onset AF and recurrence while on treatment as registered by ECG, 24 hours holter or mentioned by the treating physician.

Data on comorbidities and risk factors for AF, including diabetes mellitus, hypertension, obstructive sleep apnoea, cardiac surgery (other than ASD closure) and atrial dilatation, were collected. Left atrial volume was determined using the last available echocardiographic examination. Left atrial dilatation was echocardiographically defined as a volume $\geq 30 \mathrm{~mL} / \mathrm{m}^{2}$ but left atrial dilatation reported by the treating cardiologist was also found sufficient.
To evaluate the different $\mathrm{AF}$ treatment strategies, patients were classified according to rhythm or rate control after first diagnosis of $\mathrm{AF}$ and at the end of follow-up period. All prescribed antiarrhythmic drugs (AAD) were evaluated, including duration of treatment, recurrence of $\mathrm{AF}$ on treatment and reason of switch to other AAD. Duration of AAD used was determined as the known minimum time interval of treatment. Invasive treatment for AF was also analysed.

\section{Statistical analysis}

Continuous variables were expressed as mean $\pm \mathrm{SD}$ or median and IQR (25-75th percentile), depending on skewness and compared using independent Student's t-test or Mann-Whitney U test. Categorical variables were expressed as count (percentage) and compared using the $\mathrm{X}^{2}$ test or Fisher's exact test. A crude incidence rate for AF was calculated by dividing the number of incident cases of $\mathrm{AF}$ by the number of person-years at risk accumulated in the population without AF. A stepwise binary logistic regression analysis was used to assess independent factors associated with AF. Differences in patient characteristics between groups with $\mathrm{p}<0.05$ in univariable analyses were considered in multivariable analysis. To evaluate if closure was independently associated with development of AF, we adjusted for other significant variables that could influence the outcome of closure on development of AF.

Overall, a $\mathrm{p}<0.05$ was considered statistically significant. Statistical analysis was performed with SPSS V.25 (IBM).

\section{RESULTS}

\section{Study population}

A total of 298 patients were identified for this study. After excluding patients according to the previous mentioned exclusion criteria (one patient with only one outpatient clinical consult, one patient with an incorrect patient number and one who had a stated objection for usage of his or her clinical data for research) a total of 173 patients with an ASD were identified (figure 1). Type of ASD was ostium secundum defect in 124 patients $(71.7 \%)$, ostium primum defect in $47(27.2 \%)$ and sinus venosus defect in $2(1.2 \%)$. Thirty-four $(19.7 \%)$ patients developed newonset AF during a follow-up. The incidence rate was 4.45 per 1000 patient-years. The mean age of onset of AF was $59 \pm 14$ years. The median clinical follow-up was 43 (29-59) years. Patient characteristics are summarised in table 1A.

\section{Factors associated with AF}

Patients who had new-onset AF were significantly older in comparison to patients who did not have $\mathrm{AF}$ (56 vs $26, \mathrm{p}<0.001)$. Hypertension $(\mathrm{p}<0.001)$, obstructive sleep apnoea $(\mathrm{p}=0.049)$ and a dilated left atrium $(\mathrm{p}<0.001)$ were more prevalent in patients who developed AF. In total 15 patients died during follow-up of which 11 had $\mathrm{AF}$.

Factors associated with $\mathrm{AF}$ are listed in table 1B. In a multivariable analysis, older age (OR 1.072 per year; 95\% CI 1.040 to $1.106 ; \mathrm{p}<0.001)$ and a dilated left atrium 


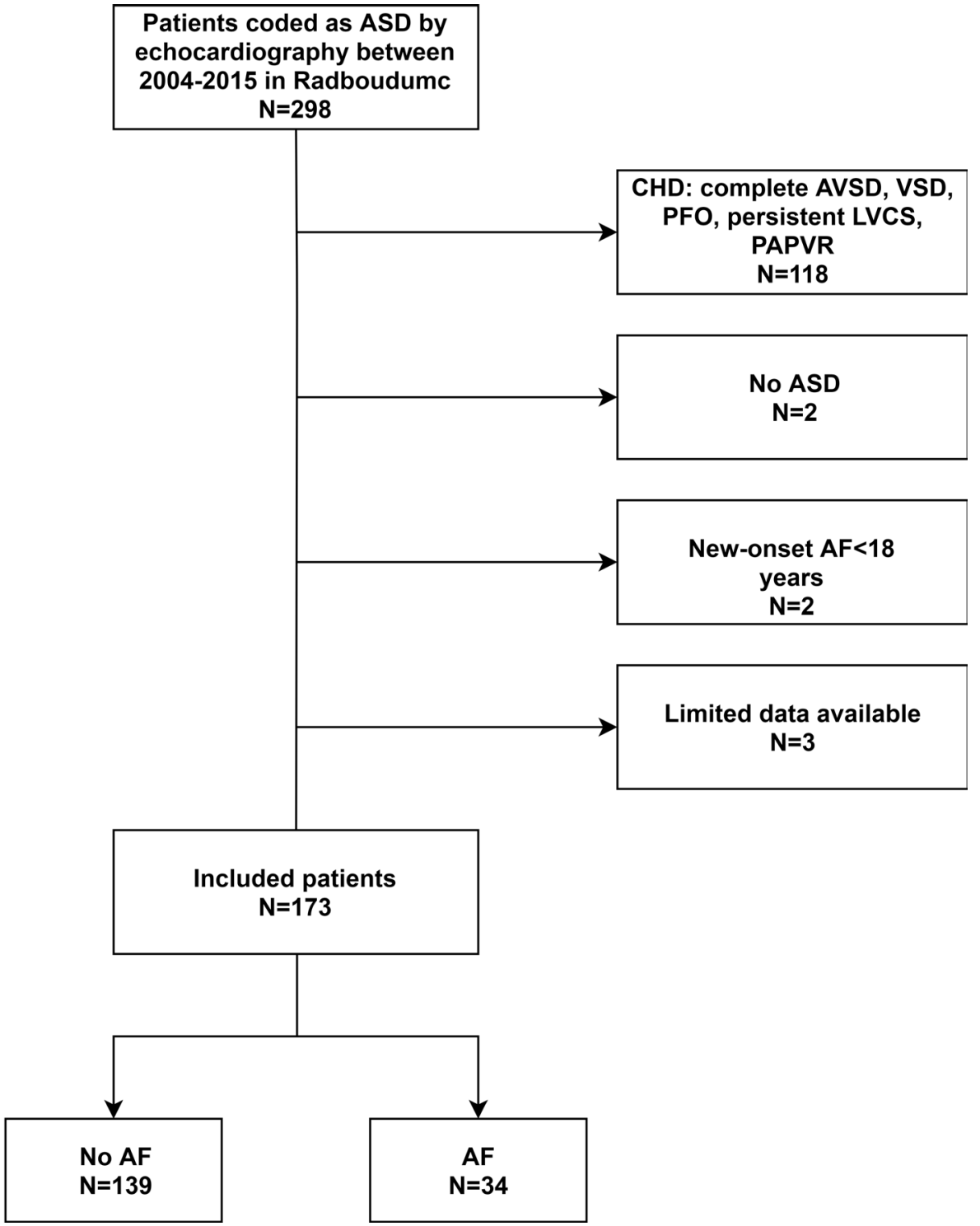

Figure 1 Inclusion flow chart. AF, atrial fibrillation; ASD, atrial septal defect; AVSD, atrioventricular septal defect; CHD, congenital heart disease; LVCS, left vena cava superior; PAPVR, partial anomalous pulmonary venous return; PFO, patent foramen ovale.

(OR 3.727; 95\% CI 1.396 to $9.951 ; \mathrm{p}=0.009$ ) were independently associated with new-onset AF.

\section{Occurrence of AF related to ASD closure}

One hundred and twenty-six of the 173 patients (72.8\%) had undergone closure during the follow-up. Of the 34 patients who developed new-onset AF, 12 never underwent ASD closure, 8 patients developed new-onset AF before closure and 14 had new-onset AF after closure. In six of the eight patients with new-onset AF before closure, $\mathrm{AF}$ was the first presentation. Seven of these eight patients had a recurrence of AF after closure.

In the patients who did not undergo ASD closure (unclosed group), 12 of the 47 (25.5\%) patients developed $\mathrm{AF}$ and in the group with closure group (closed group) 14 of the $118(11.9 \%)$ patients developed new-onset AF after closure. This difference was significant, however, patients were also younger in the ASD closure group. After adjustment for age, there was no independent association between closure and $\mathrm{AF}$ (OR 0.836 per year; 95\% CI 0.281 to $2.488 ; \mathrm{p}=0.748)$. Mean age of closure was $24( \pm 22)$ years, with a significant age difference between the groups of surgical and percutaneous closure $(18( \pm 20)$ years vs $38( \pm 22)$ years, respectively, $\mathrm{p}<0001)$. Figure 2 shows the Kaplan-Meier curves of AF free survival in the whole group and divided per ASD treatment (unclosed, surgical and percutaneous closed) group, with a significant difference for the surgical closed patients $(\mathrm{p}=0003)$. Patients who underwent closure had their first episode of $\mathrm{AF}$ at a significant younger age compared with the unclosed patient group $(55( \pm 13)$ years vs $66( \pm 13)$ years, $\mathrm{p}=0.020)$, mainly driven by the patients who underwent surgical closure (online supplementary table 1 ).

In patients who developed new-onset $\mathrm{AF}$ after closure, this occurred at median of 1 year after closure with a 
Table 1

\section{A: Patient characteristics}

\begin{tabular}{|c|c|c|c|c|}
\hline & $\begin{array}{l}\text { All patients } \\
n=173\end{array}$ & $\begin{array}{l}\text { No AF } \\
n=139\end{array}$ & $\begin{array}{l}\text { AF } \\
n=34\end{array}$ & $P$ value \\
\hline $\mathrm{Age}^{*}$ & $33(17-49)$ & $26(14-40)$ & $56(46-66)$ & $<0.001$ \\
\hline Female & $120(69.4 \%)$ & $98(70.5 \%)$ & $22(64.7 \%)$ & 0.511 \\
\hline ASD type & & & & 0.085 \\
\hline Ostium primum & $47(27.2 \%)$ & $42(30.2 \%)$ & $5(14.7 \%)$ & \\
\hline Ostium secundum & $124(71.7 \%)$ & $96(69.1 \%)$ & $28(82.4 \%)$ & \\
\hline Sinus venosus & $2(1.2 \%)$ & $1(0.7 \%)$ & $1(2.9 \%)$ & \\
\hline \multicolumn{5}{|l|}{ Closure } \\
\hline Closed† & $126(72.8 \%)$ & $104(74.8 \%)$ & $22(64.7 \%)$ & 0.235 \\
\hline Surgical & $90(52.0 \%)$ & $74(53.2 \%)$ & $16(47.1 \%)$ & \\
\hline Percutaneous & $36(20.8 \%)$ & $30(21.6 \%)$ & $6(17.6 \%)$ & $0.882 \ddagger$ \\
\hline Hypertension & $46(26.6 \%)$ & $27(19.4 \%)$ & $19(55.9 \%)$ & $<0.001$ \\
\hline Diabetes mellitus & $10(5.8 \%)$ & $7(5.0 \%)$ & $3(8.8 \%)$ & 0.415 \\
\hline Obstructive sleep apnoea & $8(4.6 \%)$ & $4(2.9 \%)$ & $4(11.8 \%)$ & 0.049 \\
\hline Left atrial dilatation & $64(37.0 \%)$ & $39(28.1 \%)$ & $25(73.5 \%)$ & $<0.001$ \\
\hline Cardiac reoperation & $14(8.1 \%)$ & $11(7.9 \%)$ & $3(8.8 \%)$ & 1 \\
\hline $\begin{array}{l}\text { Table 1B: Factors ass } \\
\text { Univariable analyses } \\
\end{array}$ & $\begin{array}{c}\text { with atrial fib } \\
\text { OR } \\
\end{array}$ & $\begin{array}{c}\text { univariable and mu } \\
95 \% \mathrm{Cl}\end{array}$ & iable analy & $P$ value \\
\hline Age, per year & 1.088 & 1.057 to 1.120 & & $<0.001$ \\
\hline Hypertension & 5.254 & 2.369 to 11.656 & & $<0.001$ \\
\hline Obstructive sleep apnoea & 4.500 & 1.065 to 19.017 & & 0.041 \\
\hline Left atrial dilatation & 7.123 & 3.053 to 16.614 & & $<0.001$ \\
\hline \multicolumn{5}{|l|}{ Multivariable analysis } \\
\hline Age, per year & 1.072 & 1.040 to 1.106 & & $<0.001$ \\
\hline Left atrial dilatation & 3.727 & 1.396 to 9.951 & & 0.009 \\
\hline
\end{tabular}

Values expressed as $\mathrm{n}(\%)$ or as median (IQR).

${ }^{*}$ Age at opening of the database (01.01.2004).

†Evaluated at end of our follow period, without regard to when AF was first diagnosed.

$\ddagger P$ value comparing method of closure on the outcome of $A F$ in the closed patients.

ASD, atrial septal defect; AF, atrial fibrillation.

widespread range of $0-32$ years and this was without difference in incidence between surgical closure and percutaneous closure $(\mathrm{p}=1)$.

\section{Treatment of AF}

Of the 34 patients with $\mathrm{AF}$, the first applied treatment strategy was known in 31 patients and of 32 patients treatment strategy at the end of follow-up was available (figure 3). One patient did not get specific treatment for AF itself. First applied treatment strategy was rhythm control in $77 \%$ (24/31), and rate control in 23\% (7/31). During the follow-up, six (19\%) patients switched from rhythm to rate control. Those who switched from rhythm to rate control, were initially treated with rhythm control for median of 65 months (range 8-205). A total of 14 patients were on rate control at the end of follow-up, of which $50 \%$ started this strategy directly at first diagnosis.
In 18 patients treated with $\mathrm{AAD}$ for rhythm control, a total of $24 \mathrm{AAD}$ were prescribed. The median duration of AAD usage was 19 months (range 2-151). These patients had a total of 16 recurrences of AF while treated with AAD. At least one recurrence occurred in 9 of the 18 patients, with a median number of 2 recurrences. Median time to first recurrence after start of first AAD was 8 months (range 1-40).

Figure 3 shows the prescribed $\mathrm{AAD}$, the amount of different drugs used, the total duration applied per drug and recurrences. Adverse events or side effects were scored if they led to a drug switch or stopping the drug.

One patient, in the rate control group, was treated with His Bundle ablation and pacemaker implantation. In five patients, additional rhythm interventions were performed: three surgical pulmonary vein isolations, of 

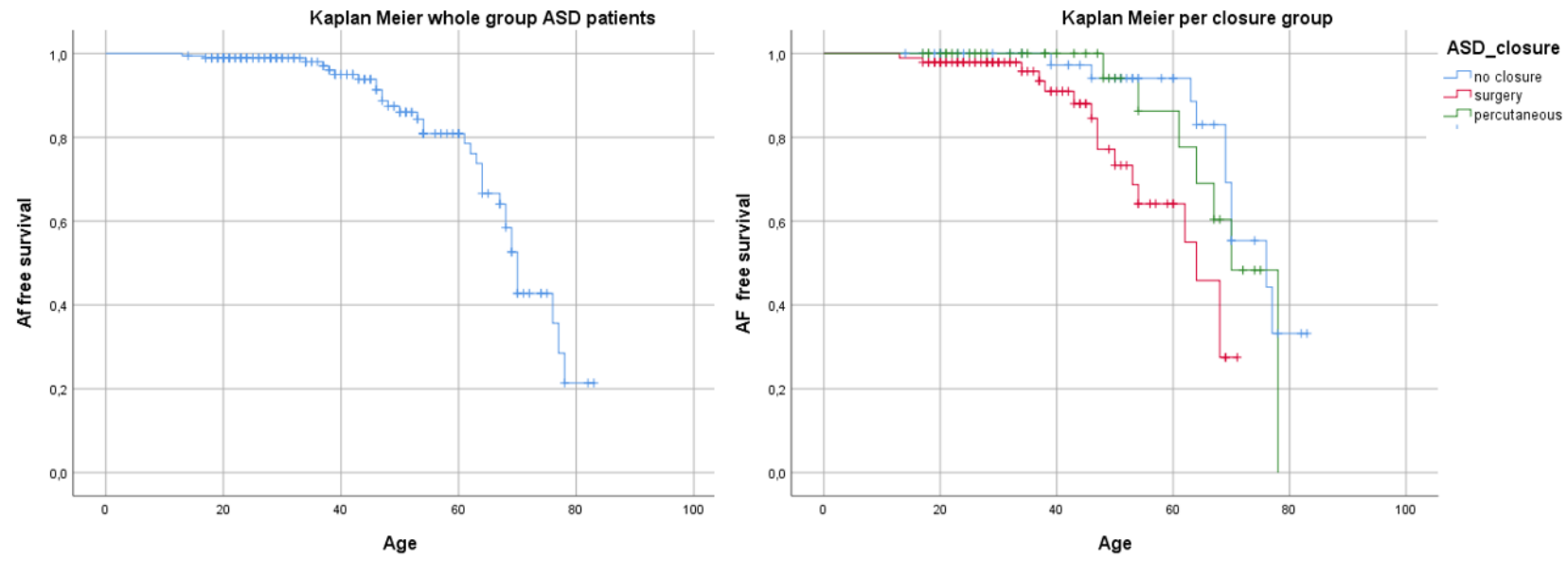

Figure 2 Kaplan-Meier curves of AF free survival. AF, atrial fibrillation; ASD, atrial septal defect.

Treatment of atrial fibrillation $(\mathrm{N}=34)$
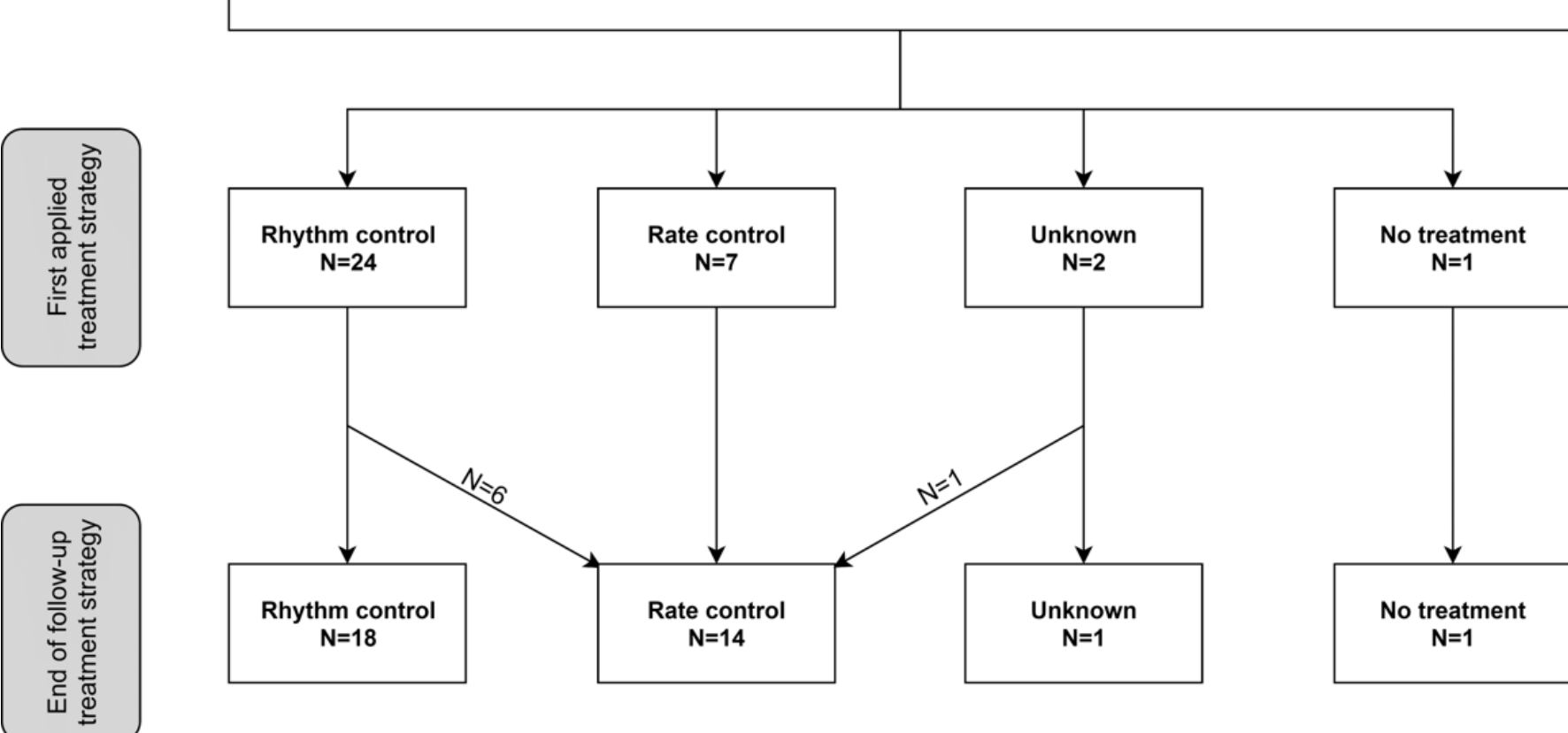

\section{Different antiarrhythmic drugs used in 18 patients}

\begin{tabular}{l|l|l|l|l|l|l|l}
\hline & Flecainide & Propafenone & Sotalol & Amiodarone & Beta-blocker & Verapamil & Total \\
\hline No. prescribed & 2 & 2 & 9 & 3 & 8 & 1 \\
\hline No. recurrences & 1 & 2 & 8 & 1 & 4 & 24 \\
\hline $\begin{array}{l}\text { Median duration } \\
\text { therapy, months }\end{array}$ & 52 & 62.5 & 13 & 24 & 11 & 16 \\
\hline $\begin{array}{l}\text { AE or side effects } \\
\text { leading to switch } \\
\text { or stop }\end{array}$ & - & - & 1 & 2 & 2 & & 30 \\
\hline
\end{tabular}

$\mathrm{AE}=$ adverse events $;$ No. $=$ number

Figure 3 Treatment strategy of atrial fibrillation and characteristics of antiarrhythmic drugs used. 


\begin{tabular}{|c|c|c|c|c|c|}
\hline & Patient 1 & Patient 2 & Patient 3 & Patient 4 & Patient 5 \\
\hline Type intervention & SurPVI & Maze & Maze & SurPVI & $\begin{array}{l}\text { SurPVI+right-sided } \\
\text { maze }\end{array}$ \\
\hline ASD type & Primum & Sinus venosus & Secundum & Secundum & Secundum \\
\hline Concurrent surgical procedure & Valve surgery & Closure ASD & Closure ASD & Closure ASD & Closure ASD \\
\hline Gender & Female & Female & Female & Female & Male \\
\hline Hypertension & Yes & Yes & No & Yes & Yes \\
\hline Diabetes mellitus & No & No & No & No & No \\
\hline Obstructive sleep apnoea & No & No & Yes & No & Yes \\
\hline Left atrial dilatation & Yes & Yes & Yes & No & Yes \\
\hline Cardiac reoperation & Yes & No & Yes & No & No \\
\hline Closure & Surgical & Surgical & Surgical & Surgical & Surgical \\
\hline Age closure, years & 5 & 66 & 69 & 52 & 35 \\
\hline Age new-onset AF, years & 38 & 61 & 68 & 48 & 34 \\
\hline Duration FU after new-onset AF, years & 3.3 & 2.3 & 7.4 & 5 & 5.9 \\
\hline Pacemaker & No & No & Yes & No & No \\
\hline Age implantation, years & & & 72 & & \\
\hline Indication & & & Symptomatic bradycardia & & \\
\hline \multicolumn{6}{|l|}{ AF treatment } \\
\hline AAD use & Yes & Yes & No & Yes & Yes \\
\hline Before and/or after intervention & Before and after & After & None & Before and After & After \\
\hline Recurrence after intervention & Yes & Yes & Yes & Yes & Yes \\
\hline Total no & 2 & 1 & 1 & 0 & 1 \\
\hline Time until first recurrence (months) & 20 & $<1$ & 1.5 years & & $<1$ \\
\hline $\begin{array}{l}\text { No of recurrences } 3 \text { months after } \\
\text { intervention }\end{array}$ & 2 & 0 & & & 0 \\
\hline Rhythm at last FU & SR (after ECV) & SR & Permanent AF & SR & SR \\
\hline$A A D$ at end $F U$ & None & Sotalol & & Metoprolol & None \\
\hline Death & No & No & Yes & No & No \\
\hline Age, years & & & 76 & & \\
\hline
\end{tabular}

$A A D$, antiarrhythmic drugs; AF, atrial fibrillation;ASD, atrial septal defect; ECV, electrical cardioversion; FU, follow-up; SR, sinusrhythm;

SurPVI, surgical pulmonary vein isolation.

which one concomitant with a right-sided maze, and two Cox maze procedures. Table 2 presents characteristics of each patient in the intervention group. These interventions were performed concurrent with other surgical procedure. These five patients were excluded for evaluation of the AAD.

A total of 10 patients had a cerebrovascular accident or transient ischaemic attack during clinical follow-up. Six in the patient group without $\mathrm{AF}$ and four in the group with AF. Three of them were already treated with oral anticoagulation and four had platelet inhibition (online supplementary table 2).

\section{DISCUSSION}

Our study confirms that patients with an ASD have a high incidence of AF. After adjusting for age, we did not find an association of closure of the ASD and the development of new onset AF. On the contrary: left atrial dilatation and advancing age were independently associated with AF in ASD patients. This is comparable to the general population of AF patients without an ASD. Nevertheless the measured incidence rate of AF in patients with ASD was still higher compared with the general population. ${ }^{4-681415}$ Besides the higher incidence of AF in ASD patients, we also showed that AF presents at a younger age, which is consistent with other studies reporting on age at AF onset in ASD patients. ${ }^{11} 16-20$

We found no difference in the incidence of AF between the surgical and percutaneous closed ASD patients, which is in concordance with other studies who did not find a difference in incidence of AF after surgical and percutaneous closure, and therefore, denying the theory that atrial scarring due to surgical closure causes $\mathrm{AF}^{8-11} 1521$ Nevertheless as these patients had surgery at a significant 
younger age, $\mathrm{AF}$ also developed at younger age compared with the percutaneous closed group. Moreover, many patients in our study had not undergone closure at all at the time of developing new-onset AF. In a meta-analysis by Vecht $e t a l,{ }^{9}$ closure was not associated with a decrease in development of AF, which is in concordance with our data of the eight patients who developed new-onset AF before closure of which seven had AF recurrences after closure. Konstantinides $e t a t^{6}$ showed that surgical closure is ineffective in the prevention of $\mathrm{AF}$ and Oliver $e t a l^{21}$ showed similar prevalence of $\mathrm{AF}$ in the surgical and nonsurgical ASD group. These data, including ours, are therefore not able to conclude that closure itself, or the method of closure is related to the development of AF. Another study by Wi et $a l^{22}$ suggested that ASD closure was effective in preventing recurrence of paroxysmal $\mathrm{AF}$, but not in patients with persistent AF. We could not confirm this in the eight patients with prior AF of which seven had a recurrence. This difference might be explained by the difference in follow-up duration, since we scored recurrence of $\mathrm{AF}$ at any time.

Although developed at younger age, an important factor associated with new-onset AF was still advancing age, which is in agreement with the general population ${ }^{23}$ as well as in other studies regarding ASD patients. ${ }^{11} 21$ Likewise a dilated left atrium was independently associated with $\mathrm{AF}$, also a known risk factor in the general population. ${ }^{24}$ There is one other study in ASD patients which also described left atrial dimension as a risk factor. ${ }^{21}$ Nevertheless, since ASD patients tend to develop AF at a younger age, other risk factors associated with the ASD may play a role. The severity of the ASD and (probably related) early indication for closure may also be of influence, since patients who underwent surgical closure in our study were at a young age at the time of closure but also had their first episode of AF at an earlier age compared with patients who did not undergo closure. Whether this is shear stress, atrial dilatation, anatomical changes, for example, fibrosis or functional changes due to the ASD remains to be clarified. Unfortunately due to the retrospective nature of our study, we could not compare groups on age itself and there is a potential selection bias for the patients who did not undergo closure. Moreover this group without ASD closure represents less than onethird of the total study population. We chose to use age of the patient at the beginning of the inclusion period of our study. We knowingly did not choose age at diagnosis of the ASD, first because it is a congenital disease and second because we hypothesised that the risk of $\mathrm{AF}$ in ASD patients lies in the disease of ASD itself, which is clinically relevant as these patients are exposed to a longer period being at risk of thromboembolic complications. Although cerebrovascular events did occur in our population, the event rate was very low and equally divided between the groups.

Another finding was a higher mortality rate in the $\mathrm{AF}$ group. In total 15 patients did not survive our follow-up, of which 11 had AF and 4 did not. Although ageing cannot completely be ruled out, $\mathrm{AF}$ might be a sign of disease progression and perhaps mortality. This is in accordance with previous papers where arrhythmias in patients with CHD are related to morbidity, impaired quality of life and mortality. ${ }^{25} 26$ Therefore, it is of great importance to treat and if possible prevent AF in ASD patients. However, the best approach to manage and treat $\mathrm{AF}$ in patients with an ASD remains unclear. In our study, population rhythm control was the preferred strategy in the vast majority. Fifty per cent of the patients treated with AAD had at least one recurrence, so medical treatment only for rhythm control of $\mathrm{AF}$ is rather disappointing in this patient group. Sotalol and betablockers were prescribed the most with a high recurrence rate. Because of the small number of patients and the recurrences seen a random moments in time as a result of the retrospective nature of the study, it is impossible to compare this with the efficacy of AAD treatment in the general population as describe previously. Only five patients had additional, more invasive rhythm interventions. Taking into account the, generally accepted, blanking period of 3 months after rhythm intervention, three of these five patients were recurrence free. In our population no other than concomitant surgical procedures were performed although several other types of invasive therapy have been described in literature and proven to be safe and effective. ${ }^{27-29}$ Our own group showed that a pulmonary vein isolation together with ASD closure in the same procedure can be performed safely with a good effect on recurrence rate in symptomatic patients with $\mathrm{AF}$ and an ASD. ${ }^{30}$ Future studies are needed on the best treatment option of AF in patients with an ASD. Both invasive and non-invasive (medical) therapy can be considered and should be investigated on its efficacy.

\section{Study limitations}

It was a single-centre retrospective study with the risk of incomplete data. The first documentation of AF might not be the actual first occurrence of AF. The relatively small sample size, small number of events and limited number of patients (less than a third) who did not undergo closure are other important limitations. The study was not designed, nor powered to analyse the thromboembolic events and anticoagulation treatment, for which the changing indication for oral anticoagulation over time has to be taken into account. Risk factors such as left atrial dilatation were retrieved at the end of follow-up. This could widely differ in time between patients related to the moment of AF.

\section{CONCLUSION}

The risk of developing AF in ASD patients is high and age at new onset is relatively young compared with patients without ASD. Nevertheless age is still an important risk factor in these patients. Closure of the defect was not clearly associated with AF: no preventive or therapeutic effect could be observed. Further studies regarding AF and ASD should consider other factors contributing 
to the vulnerability of ASD patients to develop AF and, importantly, more data is needed on treatment strategies in this specific patient population.

Contributors RE and MR contributed equally to this paper. All authors contributed to the data analysis, drafting and revising the article and gave their approval for the final version to be published. They all take responsibility for all aspects of the reliability and freedom from bias of the data presented and their discussed interpretation.

Funding The authors have not declared a specific grant for this research from any funding agency in the public, commercial or not-for-profit sectors.

Competing interests None declared.

Patient consent for publication Not required.

Ethics approval This retrospective cohort study was approved by the local ethics committee in the Radboud University Medical Centre Nijmegen (METC number 2018-4861).

Provenance and peer review Not commissioned; externally peer reviewed.

Data availability statement Data are available on reasonable request. All data relevant to the study are included in the article or uploaded as online supplementary information. The data have been stored at the hospital server.

Open access This is an open access article distributed in accordance with the Creative Commons Attribution Non Commercial (CC BY-NC 4.0) license, which permits others to distribute, remix, adapt, build upon this work non-commercially, and license their derivative works on different terms, provided the original work is properly cited, appropriate credit is given, any changes made indicated, and the use is non-commercial. See: http://creativecommons.org/licenses/by-nc/4.0/.

\section{ORCID iDs}

Reinder Evertz http://orcid.org/0000-0002-7958-3098

Anthonie L. Duijnhouwer http://orcid.org/0000-0001-5064-0143

Kevin Vernooy http://orcid.org/0000-0001-8539-3365

\section{REFERENCES}

1 van der Linde D, Konings EEM, Slager MA, et al. Birth prevalence of congenital heart disease worldwide: a systematic review and metaanalysis. J Am Coll Cardiol 2011;58:2241-7.

2 Reller MD, Strickland MJ, Riehle-Colarusso T, et al. Prevalence of congenital heart defects in metropolitan Atlanta, 1998-2005. J Pediatr 2008:153:807-13.

3 Schwedler G, Lindinger A, Lange PE, et al. Frequency and spectrum of congenital heart defects among live births in Germany : a study of the Competence Network for Congenital Heart Defects. Clin Res Cardiol 2011;100:1111-7.

4 Gatzoulis MA, Freeman MA, Siu SC, et al. Atrial arrhythmia after surgical closure of atrial septal defects in adults. N Engl J Med 1999;340:839-46.

5 Berger F, Vogel M, Kramer A, et al. Incidence of atrial flutter/ fibrillation in adults with atrial septal defect before and after surgery. Ann Thorac Surg 1999;68:75-8.

6 Konstantinides S, Geibel A, Olschewski M, et al. A comparison of surgical and medical therapy for atrial septal defect in adults. $N$ Engl $J$ Med 1995;333:469-73.

7 Murphy JG, Gersh BJ, McGoon MD, et al. Long-term outcome after surgical repair of isolated atrial septal defect-follow-up at 27 to 32 years. N Engl J Med 1990;323:1645-50.

8 Silversides CK, Haberer K, Siu SC, et al. Predictors of atrial arrhythmias after device closure of secundum type atrial septal defects in adults. Am J Cardiol 2008;101:683-7.

9 Vecht JA, Saso S, Rao C, et al. Atrial septal defect closure is associated with a reduced prevalence of atrial tachyarrhythmia in the short to medium term: a systematic review and meta-analysis. Heart 2010;96:1789-97.
10 Nyboe C, Olsen MS, Nielsen-Kudsk JE, et al. Atrial fibrillation and stroke in adult patients with atrial septal defect and the long-term effect of closure. Heart 2015;101:706-11.

11 Karunanithi Z, Nyboe C, Hjortdal VE. Long-term risk of atrial fibrillation and stroke in patients with atrial septal defect diagnosed in childhood. Am J Cardiol 2017;119:461-5.

12 Van De Bruaene A, Moons P, Belmans A, et al. Predictive model for late atrial arrhythmia after closure of an atrial septal defect. Int $J$ Cardiol 2013;164:318-22.

13 Kirchhof P, Benussi S, Kotecha D, et al. 2016 ESC guidelines for the management of atrial fibrillation developed in collaboration with EACTS. Rev Esp Cardiol 2017;70:50.

14 Cuypers JAAE, Opić P, Menting ME, et al. The unnatural history of an atrial septal defect: longitudinal 35 year follow up after surgical closure at young age. Heart 2013;99:1346-52.

15 Spies C, Khandelwal A, Timmermanns I, et al. Incidence of atrial fibrillation following transcatheter closure of atrial septal defects in adults. Am J Cardiol 2008;102:902-6.

16 Go AS, Hylek EM, Phillips KA, et al. Prevalence of diagnosed atrial fibrillation in adults: national implications for rhythm management and stroke prevention: the anticoagulation and risk factors in atrial fibrillation (atria) study. JAMA 2001;285:2370-5.

17 Heeringa J, van der Kuip DAM, Hofman A, et al. Prevalence, incidence and lifetime risk of atrial fibrillation: the Rotterdam study. Eur Heart J 2006;27:949-53.

18 Teuwen CP, Ramdjan TTTK, Götte M, et al. Time course of atrial fibrillation in patients with congenital heart defects. Circ Arrhythm Electrophysiol 2015;8:1065-72.

19 Houck CA, Evertz R, Teuwen CP, et al. Time course and interrelationship of dysrhythmias in patients with surgically repaired atrial septal defect. Heart Rhythm 2018;15:341-7.

20 Benjamin EJ, Wolf PA, D'Agostino RB, et al. Impact of atrial fibrillation on the risk of death: the Framingham heart study. Circulation 1998;98:946-52

21 Oliver JM, Gallego P, González A, et al. Predisposing conditions for atrial fibrillation in atrial septal defect with and without operative closure. Am J Cardiol 2002;89:39-43.

$22 \mathrm{Wi}$ J, Choi J-Y, Shim J-M, et al. Fate of preoperative atrial fibrillation after correction of atrial septal defect. Circ $J$ 2013;77:109-15.

23 Schnabel RB, Yin X, Gona P, et al. 50 year trends in atrial fibrillation prevalence, incidence, risk factors, and mortality in the Framingham heart study: a cohort study. Lancet 2015;386:154-62.

24 Vaziri SM, Larson MG, Benjamin EJ, et al. Echocardiographic predictors of nonrheumatic atrial fibrillation. The Framingham heart study. Circulation 1994;89:724-30.

25 Bouchardy J, Therrien J, Pilote L, et al. Atrial arrhythmias in adults with congenital heart disease. Circulation 2009;120:1679-86.

26 Khairy P, Van Hare GF, Balaji S, et al. PACES/HRS expert consensus statement on the recognition and management of arrhythmias in adult congenital heart disease: developed in partnership between the pediatric and congenital electrophysiology Society (PACES) and the heart rhythm Society (HRS). endorsed by the governing bodies of PACES, Hrs, the American College of cardiology (ACC), the American heart association (AHA), the European heart rhythm association (EHRA), the Canadian heart rhythm Society (CHRS), and the International Society for adult congenital heart disease (ISACHD). Can J Cardiol 2014;30:e1-63.

27 Santangeli P, Di Biase L, Burkhardt JD, et al. Transseptal access and atrial fibrillation ablation guided by intracardiac echocardiography in patients with atrial septal closure devices. Heart Rhythm 2011:8:1669-75

28 Nie J-G, Dong J-Z, Salim M, et al. Catheter ablation of atrial fibrillation in patients with atrial septal defect: long-term follow-up results. J Interv Card Electrophysiol 2015;42:43-9.

29 Crandall MA, Daoud EG, Daniels CJ, et al. Percutaneous radiofrequency catheter ablation for atrial fibrillation prior to atrial septal defect closure. J Cardiovasc Electrophysiol 2012;23:102-4.

30 Evertz R, Houck CA, Ten Cate T, et al. Concomitant pulmonary vein isolation and percutaneous closure of atrial septal defects: a pilot project. Congenit Heart Dis 2019;14:1123-9. 